\title{
BEHAVIORISME DALAM ATH-THARIQAH AL-INTIQAIYYAH \\ PADA PEMBELAJARAN BAHASA ARAB
}

\author{
Oleh: Mega Primaningtyas \\ Dosen STAIMS Yogyakarta
}

\begin{abstract}
Arabic language is a foreign language that has been studied in various educational institutions in Indonesia, both formal and non-formal. The purpose of learning Arabic is varied. There are three theories of knowledge in Arabic language learning underlying it, namely psychiatry (psychology), linguistics (linguistics), and science education (pedagogy). In this discussion, the author focuses on the psychological theory that behaviorism. One element is the method of learning Arabic. Methods of delivery of content is procedurally. And one of these methods is the Ath-Al-Intiqaiyyah Thariqah or eclectic method. The emergence of this method is motivated by various problems faced when learning Arabic using methods that already exist. Through the Ath-Al-Intiqaiyyah Thariqah behaviorism give its contribution to learning Arabic. Based on that that language is speech, not written, the language is formed from habits. The language to be learned, not about the language, the language is not spoken but it should be used. All languages in the world have differences. And the order in language skills should be taught as listening, speaking, reading and writing.
\end{abstract}

Keywords: behaviorism, and Ath-Thariqah Al-Intiqaiyyah

\begin{abstract}
Abstrak
Bahasa arab merupakan bahasa asing yang telah dipelajari diberbagai lembaga-lembaga pendidikan di Indonesia, baik formal maupun non formal. Adapun tujuan dalam pembelajaran bahasa Arab itu bervariasi. Ada tiga teori keilmuan dalam pembelajaran bahasa Arab yang mendasarinya, yaitu ilmu jiwa (psikologi), ilmu bahasa (linguistik), dan ilmu pendidikan (pedagogi). Dalam pembahasan kali ini, penulis menfokuskan pada teori psikologi yaitu behaviorisme. Salah satu unsur pembelajaran bahasa Arab adalah metode. Metode adalah penyampaian materi secara prosedural. Dan salah satu metode tersebut adalah Ath-Thariqah Al-Intiqaiyyah atau metode eklektik. Munculnya metode ini dilatarbelakangi oleh berbagai permasalahan yang dihadapi saat pembelajaran bahasa arab menggunakan metode-metode yang sudah ada. Melalui Ath-Thariqah Al-Intiqaiyyah behaviorisme memberikan perannya terhadap pembelajaran bahasa Arab. Berdasarkan hal tersebut bahwa bahasa merupakan ujaran, bukan tulisan, bahasa terbentuk dari kebiasaankebiasaan. Bahasa yang harus dipelajari, bukan tentang bahasa, bahasa bukan dibicarakan tetapi harus digunakan. Semua bahasa di dunia memiliki perbedaan. Dan urutan dalam keterampilan berbahasa yang harus diajarkan yaitu mendengarkan, berbicara, membaca dan menulis.
\end{abstract}

Kata Kunci : Behaviorisme, dan Ath-Thariqah Al-Intiqaiyyah

\section{A. Pendahuluan}

Bahasa Arab sebagai bahasa asing, telah diajarkan di berbagai lembaga pendidikan baik itu secara formal maupun non formal, seperti Sekolah, Kampus, Pondok Pesantren, dan lainlain. Pembelajaran bahasa Arab itu memiliki beberapa orientasi yang bervariasi, seperti 
orientasi religi, orientasi akademis, orientasi professional dan pragmatis serta orientasi ideologis dan ekonomis.

Terkait dengan pembelajaran Bahasa, Khususnya bahasa Arab, ada beberapa dasar-dasar teoritis yang mendasarinya, yaitu Teori-teori ilmu jiwa (psikologi), teori-teori ilmu bahasa (linguistik), dan teori-teori pendidikan (pedagogi). Ketiga teori ini memberikan kontribusi yang besar terhadap pembelajaran bahasa arab dalam hal penentuan tujuan pembelajaran, metode pembelajaran, bahan ajar, evaluasi pembelajaran dan lain-lain.

Metode pembelajaran bahasa Arab yang berhubungan erat dengan langkah-langkah penyampaian materi secara prosedural sesuai dengan pendekatan yang digunakan, tidak bisa terlepas dari kontribusi tiga landasan teori yang telah disebutkan, diantara dua landasan itu adalah psikologi dan linguistik, yang menjadi fokus dalam tulisan ini.

Diantara teori ilmu jiwa (Psikologi) yang memberikan kontribusi terhadap perkembangan metode pembelajaran bahasa Arab salah satunya adalah teori behaviorisme yang digagas oleh Pavlov, teori Nativisme yang ikuti oleh Chomsky, dan teori-teori yang lain.

Dari uraian di atas, dalam tulisan ini akan membahas tentang salah satu teori psikologi dan linguistik yang memberikan perannya terhadap metode Intiqaiyyah atau metode eklektik dalam pembelajaran bahasa Arab, adapun teori psikologinya adalah teori behaviorisme.

\section{B. Tokoh-tokoh Behaviorisme dan pandangannya terhadap pembelajaran bahasa}

1. Tokoh-tokoh dalam Behaviorisme

Menurut teori tingkah laku, belajar adalah perubahan dalam tingkah laku sebagai akibat dari interaksi antara stimulus dan respon. Atau lebih tepat perubahan yang dialami siswa dalam hal kemampuan untuk bertingkah laku dengan cara yang baru sebagai hasil interaksi antara stimulus dan respon. Meskipun semua penganut aliran ini setuju dengan premis dasar ini, namun mereka berbeda dalam beberapa hal penting.Tokoh-tokohnya antara lain :

a. Edward L. Thorndike

Psikologi aliran behavioristik mulai mengalami perkembangan melalui lahirnya teoriteori tentang belajar yang dipelopori oleh Edward L. Thordike (1874-1949) pertama kalinya tentang kecerdasan hewan (Animal Intelijent ) pada 1898.

Menurut Thorndike, belajar adalah proses interaksi antara stimulus dan respon. Stimulus adalah apa yang merangsang terjadinya kegiatan belajar seperti pikiran, perasaan, atau hal-hal lain yang dapat ditangkap melalui alat indera. Sedangkan respon adalah reaksi yang dimunculkan peserta didik ketika belajar, yang dapat pula berupa pikiran, perasaan, atau gerakan/tindakan. Jadi perubahan tingkah laku akibat kegiatan belajar dapat berwujud 
konkrit, yaitu yang dapat diamati, atau tidak konkrit yaitu yang tidak dapat diamati. Meskipun aliran behaviorisme sangat mengutamakan pengukuran, tetapi tidak dapat menjelaskan bagaimana cara mengukur tingkah laku yang tidak dapat diamati. Teori Thorndike ini disebut pula dengan teori koneksionisme (Slavin, 2000) ${ }^{1}$.

Ada tiga hukum belajar yang utama, menurut Thorndike yakni (1) hukum efek; (2) hukum latihan dan (3) hukum kesiapan (Bell, Gredler, 1991). Ketiga hukum ini menjelaskan bagaimana hal-hal tertentu dapat memperkuat respon.

b. Robert M. Gagne

Lahir pada 21 Agustus 1918.Teori belajar Hierarki Gagne didasarkan pada pembelajaran yang merupakan faktor sangat penting dalam perkembangan. Perkembangan merupakan hasil kumulatif dari pembelajaran. Menurut Gagne bahwa dalam pembelajaran terjadi proses penerimaan informasi, untuk kemudian diolah sehingga menghasilkan keluaran dalam bentuk hasil belajar. Dalam pemrosesan informasi terjadi adanya interaksi antara kondisi-kondisi internal dan kondisi-kondisi eksternal individu. Kondisi internal yaitu keadaan dalam diri individu yang diperlukan untuk mencapai hasil belajar dan proses kognitif yang terjadi dalam individu. Sedangkan kondisi eksternal adalah rangsangan dari lingkungan yang mempengaruhi individu dalam proses pembelajaran. Hal ini memunculkan pemikiran Gagne bahwa pembelajaran harus dikondisikan untuk memunculkan respons yang diharapkan.

Gagne mencatat ada delapan tipe belajar :

1. Belajar isyarat (signal learning)

2. Belajar stimulus respon

3. Belajar merantaikan (chaining)

4. Belajar asosiasi verbal (verbal Association)

5. Belajar membedakan (discrimination)

6. Belajar konsep (concept learning)

7. Belajar dalil (rule learning)

8. Belajar memecahkan masalah (problem solving)

\section{c. B.F. Skinner}

B.F. Skinner (104-1990) berkebangsaan Amerika dikenal sebagai tokoh behavioris dengan pendekatan model instruksi langsung (directed instruction) dan meyakini bahwa perilaku dikontrol melalui proses operant conditioning. Gaya mengajar guru dilakukan

${ }^{1}$ Robert Slavin, Psikologi Pendidikan: Teori dan Praktek, (Jakarta: Indeks Publisher, 2000) hlm. 128-130 
dengan beberapa pengantar dari guru secara searah dan dikontrol guru melalui pengulangan (drill) dan latihan (exercise).

Manajemen kelas menurut Skinner adalah berupa usaha untuk memodifikasi perilaku (behavior modification) antara lain dengan penguatan (reinforcement) yaitu memberi penghargaan pada perilaku yang diinginkan dan tidak memberi imbalan pada perilaku yang tidak tepat.

Operant Conditioning atau pengkondisian operan adalah suatu proses penguatan perilaku operan (penguatan positif atau negatif) yang dapat mengakibatkan perilaku tersebut dapat berulang kembali atau menghilang sesuai dengan keinginan.

Perilaku operan adalah perilaku yang dipancarkan secara spontan dan bebas berbeda dengan perilaku responden dalam pengkondisian Pavlov yang muncul karena adanya stimulus tertentu. Contoh perilaku operan yang mengalami penguatan adalah: anak kecil yang tersenyum mendapat permen oleh orang dewasa yang gemas melihatnya, maka anak tersebut cenderung mengulangi perbuatannya yang semula tidak disengaja atau tanpa maksud tersebut. Tersenyum adalah perilaku operan dan permen adalah penguat positifnya.

Beberapa prinsip belajar Skinner antara lain:

1. Hasil belajar harus segera diberitahukan kepada siswa, jika salah dibetulkan, jika benar diberi penguat.

2. Proses belajar harus mengikuti irama dari yang belajar.

3. Materi pelajaran, digunakan sistem modul.

4. Dalam proses pembelajaran, lebih dipentingkan aktivitas sendiri.

5. Dalam proses pembelajaran, tidak digunakan hukuman. Namun ini lingkungan perlu diubah, untuk menghindari adanya hukuman.

6. Tingkah laku yang diinginkan pendidik, diberi hadiah, dan sebagainya. Hadiah diberikan dengan digunakannya jadwal variable rasio reinforcer.

7. Dalam pembelajaran, digunakan shaping.

\section{d. Ivan Petrovich Pavlov}

Pavlov lahir 14 September 1849 di Ryyaza, Rusia.Ia Mengemukakan bahwa dengan menerapkan strategi ternyata individu dapat dikendalikan melalui cara stimulus alami dengan stimulus yang tepat untuk mendapat pengulangan respon yang diinginkan,sementara individu tidak menyadari bahwa ia dikendalikan oleh stimulus yang berasal dari luar dirinyaPavlo melakukan percobaan terhadap anjing yang diberi stimulis bersyarat sehingga terjadi reaksi 
bersyarat pada anjing.Dari hasil percobaan,sinyal (pertanda)sangat penting dalam adaptasi hewan terhadap sekitarnya.

Belajar menurut teori ini adalah suatu proses perubahan yang terjadi kerena adanya syarat-syarat yang menimbulkan reaksi.Yang terpenting dalam belajar menurut teori ini adalah adanya latihan dan pengulangan.Kelemahan teori ini adalah belajar hanyalah terjadi secara otomatis keaktifan dan penentuan pribadi dihiraukan.

\section{e. David Ausubel}

Lahir pada 25 Oktober 1918 di Brooklyn New York.Belajar menurut Ausubel adalah proses internal yang tidak dapat diamatisecara langsung. Perubahan terjadi dalam kemampuan seseorang untuk bertingkahlaku dan berbuat dalam situasi tertentu, perubahan dalam tingkah laku hanyalahsuatu reflek dari perubahan internal (berbeda dengan aliran behaviorisme, alirankognitif mempelajari aspek-aspek yang tidak dapat diamati secara langsungseperti, pengetahuan, arti, perasaan, keinginan, kreativitas, harapan dan pikiran).

Belajar bermakna menurut Ausubel merupakan suatu proses dikaitkannya informasi barupada konsep-konsep relevan yang terdapat dalam struktur kognitif seseorangfaktor yang paling penting yang mempengaruhi belajar adalah apa yang telahdiketahui siswa.Pandangan Ausubel agak berlawanan dengan Burner yang beranggapanbahwa belajar dengan menemukan sendiri (discovery learning) adalah sesuaidengan hakikat manusia sebagai seorang yang mencari-cari secara aktif danmenghasilkan pengetahuan serta pemahaman yang sungguh-sungguh bermakna Sedang menurut Ausubel kebanyakan orang belajar terutama dengan menerimadari orang lain (reception learning).

Kedua pandangan tersebut sangat mirip yakni sebuah konstruksi pengetahuan baru yang sesungguhnya bergantung pada sistem pembelajaran yang bermakna. Hanya saja discovery learning Burner menonjolkan corak berpikir induktif sedangkan reception learning Ausubel menonjolkan corak berpikirdeduktif. Sebagai konsekuensinya, Ausubel mencanangkan mengajar yangdisebutkan "mengajar dengan menguraikan" (expository teaching). Psikologi pendidikan yang diterapkan oleh Ausubel adalah bekerja untuk mencari hukum belajar yang bermakna ${ }^{2}$.

\footnotetext{
${ }^{2}$ Nazri Syakur, Diktat Kuliah: Psikologi Belajar Bahasa, (Yogyakarta: UIN Sunan Kalijaga, 2006) hlm. 133
} 


\section{f. Baruda}

Baruda mengemukakan bahwa siswa belajar itu melalui meniru. Pengertian meniru di sini bukan berarti menyontek, tetapi meniru hal-hal yang dilakukan oleh orang lain, terutama guru. Jika tulisan guru baik, guru berbicara sopan santun dengan menggunakan hahasa yang baik dan benar, tingkah laku yang terpuji, menerangkan dengan jelas dan sistematik, maka siswa akan menirunya. Jika contoh-contoh yang dilihatnya kurang baik ia pun menirunya. Dengan demikian guru harus menjadi manusia model yang profesional. Teori social learning (belajar sosial), anak belajar dari meniru hal-hal yang dilakukan oleh orang lain. Dengan demikian, lingkungan adalah faktor penting yang mempengaruhi perilaku, meskipun proses kognitif juga tidak kalah pentingnya manusia memiliki kemampuan untuk mengendalikan polanya sendiri ${ }^{3}$.

2. Pandangan Behaviorisme dalam pembelajaran bahasa

Teori behaviorisme beranggapan bahwa bahasa diperoleh melalui proses pengulangan bahasa. Ia dikuasai melalui rangsangan dan gerak balas. Golongan dalam teori ini mementingkan pengukuhan dalam pembelajaran yang dapat ditimbulkan melalui ganjaran. Dalam konteks pengajaran dan pembelajaran bahasa, teori ini menegaskan latihan dan latih tubi pola (bermula daripada senang kepada yang lebih susah). Teori ini juga menekankan kemahiran lisan dalam pengajaran. Prinsip-prinsip pengajaran bahasa dari golongan ini adalah dari pandangan dan pendapat ahli-ahli psikologi dan linguistik aliran Behaviorisme.

Golongan ini beranggapan bahwa; Pertama, bahasa yang diutamakan ialah bahasa lisan manakala bahasa tulisan merupakan bahasa kedua penting. Ahli-ahli Behaviorisme menegaskan bahawa pengajaran bahasa mestilah didahulukan bahasa lisan. Kemudian pembelajaran bahasa tulisan yang dianggap perkara penting yang kedua dalam proses pengajaran dan pembelajaran. Hal ini bermakna guru-guru berusaha untuk membolehkan murid-murid bertutur dalam bahasa itu dahulu dan kemudian dilanjutkan kepada pengajaran membaca dan menulis setelah murid-murid dapat menguasai sistem bahasa dan struktur bahasa. Kedua, bahasa adalah satu tabiat. Prinsip ini sesuai diterapkan dalam proses pembelajaran kedua. Guru perlu menyusun pelajaran dengan baik dan pengajaran dimulai dengan pola-pola yang mudah ke pola yang lebih susah. Ketiga, apresiasi adalah satu syarat penting di dalam pembelajaran yang merupakan satu alat untuk menentukan pembentukan tingkah laku yang dikehendaki. Dalam situasi pembelajaran bahasa memberikan pujian atas capaian siswa dalam pembelajaran menjadi sangat penting, hal ini akan terus memacu

${ }^{3}$ http://library.um.ac.id/free-contents/index.php/buku/detail/cooperative-learning-teori-riset-dan-praktik-robert-e-slavin-45380.html akses 16 Mei 2016 
semangat siswa dalam belajar bahasa. Keempat, latihan pembelajaran adalah latihan yang bersifat terus menerus. Hal ini merupakan latihan tanya jawab dengan lawan bicara . Latihan ini hendaklah dilakukan dalam keadaan yang bermakna. Ini adalah untuk meningkatkan kemampuan berbahasa agar tidak merasa jenuh ${ }^{4}$.

Dalam hal ini, satu model pembelajaran telah dikemukakan oleh Behaviorisme yaitu : Latihan yang dikukuhkan -> pembelajaran -> perubahan tingkah laku

Kaum behaviorisme mengaplikasikan hukum behaviorisme ini terhadap pemerolehan bahasa dan pembelajarannya. Mereka melakukan langkah ini berdasarkan pendapatnya bahwa pemerolehan bahasa ini tidak berbeda dengan pemerolehan tingkah laku lainnya, begitu juga dalam hal belajar. Anak memperoleh bahasanya, menurut pendapat mereka berdasarkan adat dan kebiasaan serta penguat positif dari kedua orang tua, guru, atau orang yang berada disekitarnya, ketika ia mengucapkan kalimat dengan benar untuk pertama kalinya. Ini terjadi berdasarkan penguat negative berupa pemberian sanksi secara langsung atau tidak langsung untuk menjaga agar anak bisa menjawab pertanyaaan dengan benar dan menghindari kesalahan.

Behaviorisme berpendapat bahwa perilaku terbentuk melalui rangsangan (stimulus) dan tindak balas (respons). Oleh sebab itu, maka dapat dikatakan bahwa perubahan perilaku lebih banyak dipengaruhi oleh lingkungan ${ }^{5}$.

\section{Sejarah munculnya Ath-Thariqah Al-Intiqaiyyah}

Pengajaran bahasa asing selalu menghadapi kondisi objektif yang berbeda-beda antara satu negeri dengan yang lain, antara satu lembaga dengan lembaga yang lain, antara satu kurun waktu dan kurun waktu yang lain. Kondisi objektif itu meliputi tujuan pengajaran, keadaan guru, keadaan siswa, sarana prasarana dan lain sebagainya. Dan berdasarkan kenyataan diatas muncullah metode Eklektik yang mengandung arti pemilihan dan penggabungan ${ }^{6}$.

Metode eklektik adalah metode pilihan dan gabungan dari dua metode atau lebih. Eklektik adalah istilah yang kadang-kadang digunakan bagi praktek pemakaian ciri-ciri

\footnotetext{
${ }^{4}$ Patsy M.Lightbown dan Nina Spada, How Languages Are Learned, (China: Oxford University Press, 2000) hlm.31-35

${ }^{5}$ Ibid, hlm. 35-36

${ }^{66}$ Azhar Arsyad, Bahasa Arab dan Metode Pengajarannya, (Yogyakarta: Pustaka Pelajar, 2004) hlm.66
} 
beberapa metode yang berbeda dalam pengajaran bahasa. Metode eklektik, mengandung arti pemilihan dan penggabungan. Di dalam bahasa Arab, metode ini disebut dengan beberapa nama, antara lain, Thariqah al-Intiqo'iyyah ( الطريقة اللإنتقائية ), Mukhtarah ( الطريقة المختارة ), Taufiqiyyah ( الطريقة التوفيقية), Mazdujah( الطريقة المزدوجة). Perlu ditegaskan bahwa penggabungan metode-metode ini hanya bisa dilakukan antar metode yang sehaluan. Dua metode yang asumsinya atau tujuannya bertolak belakang tentu tidak tepat untuk digabungkan ${ }^{7}$.

Metode eklektik berkaitan erat dengan subjektifitas pengajar. Sang pengajar seringkali dihadapkan dengan keharusan hanya memilih prosedur yang paling esensial untuk dipakai di dalam kelas dengan cara yang paling efisien. melukiskan secara tepat kaitan erat antara eklektisisme dengan subjektifisme sebagai yang tidak "memberi sesuatu bimbingan mengenai dasar apa dan dengan prinsip-prinsip apa", semua aspek metode-metode yang berbeda itu dapat diseleksi dan dikombinasikan, dapat dipilih dan digabung. Al-'araby (1981) menjelaskan, metode eklektik ini bisa menjadi metode yang ideal apabila didukung oleh penguasaan guru secara memadai terhadap berbagai macam metode, sehingga dapat mengambil secara tepat segi-segi kekuatan dari setiap metode dan menyesuaikannya dengan kebutuhan program pengajaran yang ditanganinya, kemudian menerapkannya secara proporsional $^{8}$.

Sebaliknya metode eklektik bisa menjadi metode "seadanya" atau metode "semau guru" apabila pemilihannya hanya berdasarkan "selera guru" ataudasar "mana yang paling enak dan paling mudah" bagi guru. Akan tetapi, dari arti etimologi "eklektik" dan beberapa uraian di atas, kami dapat menyimpulkan bahwa metode eklektik itu adalah metode pilihan dan gabungan dari dua metode atau lebih. Di dalam bahasa Arab metode ini disebut dengan beberapa nama, antara lain:

$$
\text { الطريقة الإنتقائية، الطريقة المختارة، الطريقة التوفيقية، الطريقة المزدوجة }
$$

Metode ini didasarkan atas asumsi bahwa :

1. Tidak ada metode yang ideal karena masing-masing mempunyai segi-segi kekuatan dan kelemahan.

\footnotetext{
${ }^{7}$ Radliyah zaenuddin, metodologi dan strategi alternatif pembelajaran bahasa arab, (yogyakarta: pustaka rihlah, 2005) hlm.43

${ }^{8}$ Muhbib Abdul Wahab, Epistemologi dan Metodologi Pembelajaran Bahasa Arab, (Jakarta: UIN Syarif Hidayatullah, 2008) hlm.135-138
} 
2. Setiap metode mempunyai kekuatan yang dimanfaatkan untuk mengefektifkan pengajaran.

3. Lahirnya metode baru harus dilihat tidak sebagai penolakan kepada metode lainnya melainkan sebagai penyempurnaan.

4. Tidak ada satu metode yang cocok untuk semua tujuan,semua guru,semua siswa, dan semua program pengajaran.

5. Yang terpenting dalam pengajaran adalah memenuhi kebutuhan pelajar, bukan memenuhi kebutuhan suatu metode

6. Setiap guru memiliki kewenangan dan kebebasan untuk memilih metode yang sesuai dengan kebutuhan pelajar.

Metode Eklektik ini bisa menjadi metode yang ideal apabila didukung oleh penguasaan guru secara memadai terhadap berbagai macam metode, sehingga dapat mengambil secara tepat segi-segi kekuatan dari setiap metode dan menyesuaikannya dengan kebutuhan program pengajaran yang ditanganinya, kemudian menerapkannya secara proposional.

Sebaliknya metode Eklektik bisa menjadi metode seadanya atau metode "semau guru" apabila pemilihannya hanya berdasarkan "selera" guru, atau atas dasar "mana yang paling enak atau mana yang paling mudah" bagi guru. Bila demikian halnya, maka hal yang terjadi adalah ketidakmenentuan, dan tidak bias diharapkan hasil yang memadai dari hasil pembelajaran yang tidak menentu.

Perlu ditegaskan bahwa penggabungan metode-metode ini hanya bisa dilakukan antarmode yang sehaluan. Dua metode yang asumsinya atau tujuannya bertolak belakang tentu tidak tepat untuk digabungkan. Penggabungan juga lebih tepat dilakukan dalam tataran teknik atau operasional ${ }^{9}$.

\section{Ciri-ciri penggunaan Ath-Thariqah Al-Intiqaiyyah}

Adapun ciri-ciri dari pengajaran bahasa dengan menggunakan metode eklektik adalah:

1. Kemahiran berbahasa diajarkan dengan urutan bercakap, menulis, memahami dan membaca.

\footnotetext{
${ }^{9}$ Ahmad Fuad Effendi, Metodologi Pengajaran Bahasa Arab, (Malang: Misykat, 2005) hlm. 71-72
} 
2. Kegiatan belajar di kelas berupa latihan (oral practice), membaca keras (reading aloud) dan Tanya jawab.

3. Dalam metode ini juga terdapat latihan menterjemahkan pelajaran gramatika secara dedukatif.

4. Digunakan alat-alat atau audio visual.

Sebagai suatu metode yang mengkombinasikan berbagai metode pengajaran, tentunya diharapkan agar kelemahan dari masing-masing metode secara terpisah dapat terhindari dan sebaliknya guru dapat dapat memaksimalkan keuntungan masing-masing metode tersebut, tentunya berdasarkan asumsi guru yang bersangkutan serta mempunyai pengetahuan tentang berbagai metode yang digunakan secara baik ${ }^{10}$.

Lebih jelasnya, berikut kelebihan pengajaran bahasa dengan menggunakan metode eklektik, yaitu:

1. Guru dapat membuat pengajaran lebih bervariasi dan lebih menarik

2. Masalah perbedaan individu, materi lingkungan belajar yang kurang menarik dapat dipecahkan.

3. Guru dapat lebih percaya diri dan meyakinkan dalam mengajarkan keterampilan berbahasa.

4. Dapat digalakkan keaktifan siswa belajar dengan sistem CBSA.

5. Guru dapat menyampaikan materi pelajaran secara lebih cepat.

6. Guru dapat menghidupkan suasana belajar mengajar di kelas.

7. Siswa akan bersemangat dalam belajar/tidak cepat jenuh

8. Dapat lebih membuat siswa berkonsentrasi pada pelajaran.

\section{E. Aplikasi penggunaan Ath-Thariqah Al-Intiqaiyyah}

Beberapa ahli pengajaran bahasa di Amerika dan Eropa menyarankan beberapa model yang menjembatani latihan-latihan manipulatif dengan latihan-latihan komunikatif. Sadtono (1978) menyarankan agar porsi manipulatif dan komunikatif dalam pengajaran diatur secara gradual seperti gambar berikut ini ${ }^{11}$ :

\footnotetext{
${ }^{10}$ Sri Utari Subyakto- Nababan, Metodologi Pengajaran Bahasa, (Jakarta: Gramedia, 1993) hlm. 10-12

${ }^{11}$ Ahmad Fuad Effendi, Metodologi Pengajaran Bahasa Arab,(Malang: Misykat,2005) hlm.73-76
} 


\begin{tabular}{|l|l|}
\hline \multicolumn{1}{|c|}{ Level } & \multicolumn{1}{|c|}{ Peran guru } \\
\hline Elementary & $100 \%$ manupulatif \\
\cline { 2 - 2 } Itermediate Advance & $\begin{array}{l}75 \% \text { manipulatif } \\
\end{array}$ \\
\cline { 2 - 2 } & $25 \%$ komunikatif \\
\cline { 2 - 2 } & $25 \%$ manipulatif \\
& $75 \%$ komunikatif \\
\cline { 2 - 2 } & $100 \%$ komunikatif \\
\hline \multicolumn{2}{|c|}{ Peran siswa } \\
\hline
\end{tabular}

Paulston 1971 mengenalkan tiga corak drill:

$\Rightarrow$ Manipulatif $\sim$ bermakna komunikatif

Rivers 1973 menggunakan istilah lain:

$\Rightarrow$ Manipulatif $\sim$ semi komunikatif $\sim$ komunikasi

Contoh drill manipulatif:

ماجد يذهب الى المدرسة ب.....

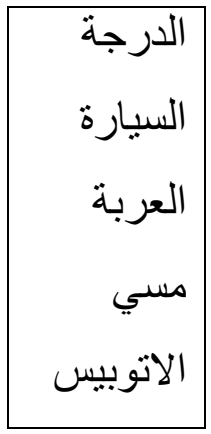

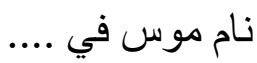

\begin{tabular}{|c|}
\hline الحمام \\
الحدرسة \\
البستانة \\
\hline
\end{tabular}

يجر الولد ........ البستان

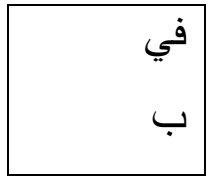




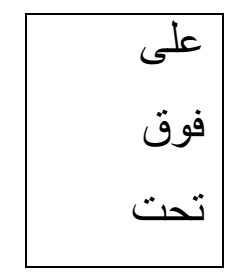

Drill secara semi- komunikatif

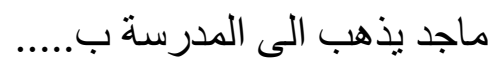
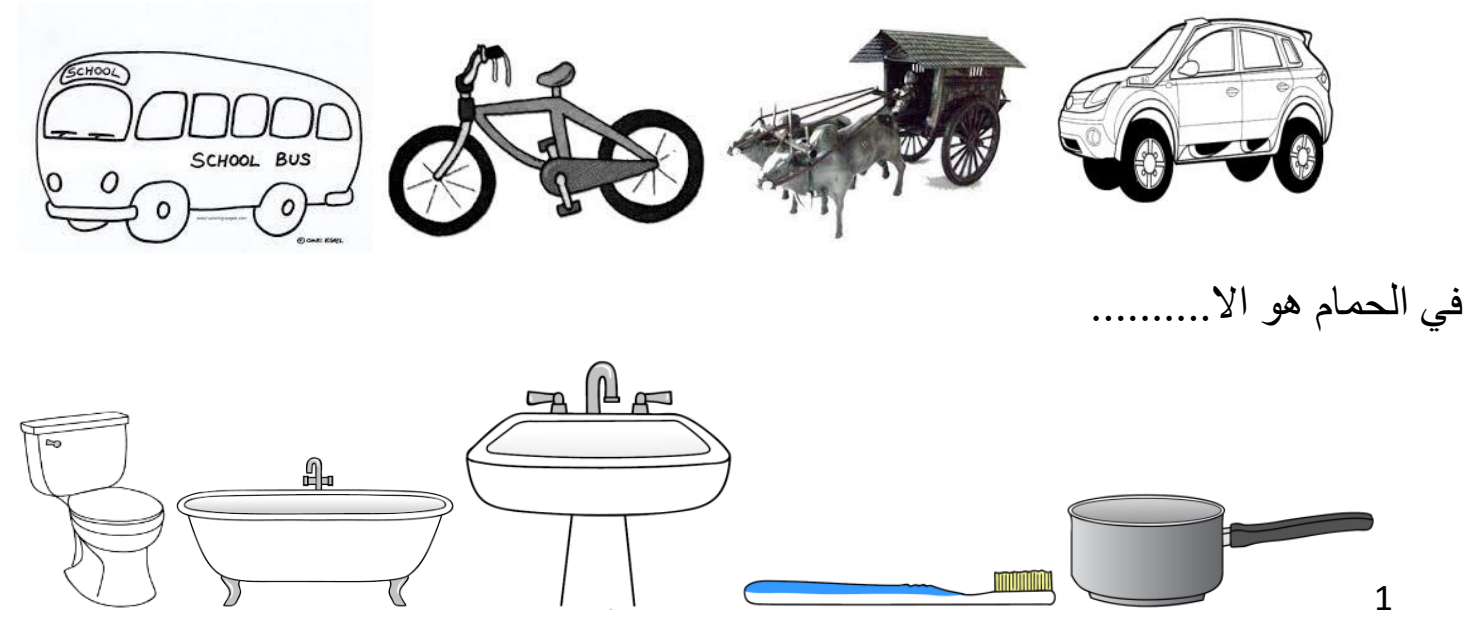

Drill komunikatif

$$
\begin{aligned}
& \text { المدرس انا اذهب الى المدرسة بالاوتوبيس, و انت يا ماجد؟ }
\end{aligned}
$$

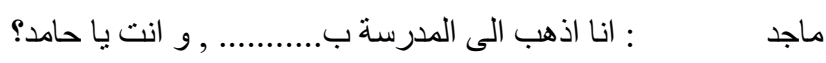

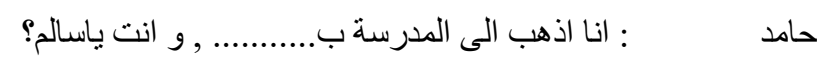

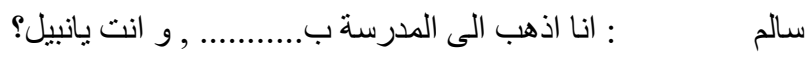

$$
\begin{aligned}
& \text { نبيل انا اذهب الى المدرسة ب................ و انت يا .... ؟ }
\end{aligned}
$$

Penyingkatan jarak waktu antara latihan manipulatif dan latihan komunikatif. Dalam metode audio lingual murni, latihan-latihan manipulatif mekanistis bisa berjalan lebihh dari 16 minggu, baru setelah itu diberikan latihan komunikatif. Dalam metode eklektik, jarak tersebut bisa dipersingkat. Tiga jenis drill diatas dapat diberikan pada jam pelajaran yang sama.

Modifikasi dan pengembangan bahan ajar, sebagai misal untuk materi tata bahasa dari deduktif menjadi induktif, dari pengetahuan menjadi penerapan. Untuk materi percakapan, dari materi berbentuk dialog untuk dihafalkan, dikembangkan menjadi atau ditambah dengan materi latihan yang kongkrit dan kontekstual. Materi bacaan yang dalam audiolingual 
ditekankan pada pelafalan dan penguasaan pola-pola kalimatnya, dikembangkan dengan latihan-latihan analisis model metode membaca dan seterusnya.

Bentuk penggabungan yang lain bisa berupa penambahan porsi latihan membaca dan menulis, yang dalam pendekatan komunikatif kurang diperhatikan. Hal ini berkaitan dengan kenyataan bahwa sebagian besar masyarakat indonesia lebih memerlukan kemampuan membaca daripada kemampuan berbicara.

\section{F. Kesimpulan}

Teori behaviorisme adalah teori belajar yang lebih menekankan pada tingkah laku manusia. Pengalaman dan pemeliharaan akan membentuk perilaku mereka. Uji coba yang dilakukan Pavlov terhadap air liur anjing dapat ditentukan syarat-syarat eksperimen pendidikan yang sesuai dengan asas-asas aliran behaviorisme seperti stimulus, respons, dan reinforcement.

Prinsip prinsip teori behaviorisme :

1. Obyek psikologi adalah tingkah laku

2. semua bentuk tingkah laku di kembalikan pada reflek

3. mementingkan pembentukan kebiasaan

Sebuah pengajaran di kelas dengan penerapan teori behaviorisme. Guru memberikan sebuah stimulus berupa materi - materi pengajaran dan mengharapkan akan mendapatkan sebuah respon yang berupa perubahan tingkah laku dari murid-muridnya. Perubahan tingkah laku dalam bentuk dari ketidaktahuan dan ketidakmampuan untuk mempraktekkan pelajaran yang diberikan berubah menjadi mampu untuk mempraktekkannya. Guru tidak melihat bagaimana proses murid-murid mencerna materi pengajaran, guru hanya melihat bagaimana hasil akhir yang diperoleh. Reinforcement positive atau negative yang akan diberikan tergantung dari bagaimana perubahan tingkah laku yang dihasillkan.

Teori behaviorisme dalam pemerolehan bahasa

1. Meniru

2. Berbicara secara serampangan untuk meminta sesuatu kepada orang-orang yang ada disekitarnya

3. Mengulang

Behaviorisme dalam pembelajaran bahasa asing dapat membantu untuk meningkatkan kemampuan siswa dalam kemahiran berbahasa. Karena adanya pengulangan-pengulangan dan peniruan, serta mencoba untuk menggunakan bahasa yang sedang dipelajari dapat membantu dalam penguasaan bahasa yang sedang dipelajari. Dalam hal ini ath-thariqah al- 
intiqaiyyah memberikan sebuah cara untuk mempelajari bahasa arab dengan model yang lebih variatif sehingga tidak merasa bosan dalam mempelajari bahasa arab.

\section{DAFTAR PUSTAKA}

Ahmad Fuad Effendi, Metodologi Pengajaran Bahasa Arab, Malang: Misykat, 2005

Azhar Arsyad, Bahasa Arab dan Metode Pengajarannya, Yogyakarta: Pustaka Pelajar, 2004

http://library.um.ac.id/free-contents/index.php/buku/detail/cooperative-learning-teori-risetdan-praktik-robert-e-slavin-45380.html

Muhbib Abdul Wahab, Epistemologi dan Metodologi Pembelajaran Bahasa Arab, Jakarta: UIN Syarif Hidayatullah, 2008

Patsy M.Lightbown dan Nina Spada, How Languages Are Learned, China: Oxford University Press, 2000

Radliyah Zaenuddin, Metodologi dan Strategi Alternatif Pembelajaran Bahasa Arab, Yogyakarta: pustaka rihlah, 2005

Robert Slavin, Psikologi Pendidikan: Teori dan Praktek, (Jakarta: Indeks Publisher, 2000)

Sri Utari Subyakto- Nababan, Metodologi Pengajaran Bahasa, Jakarta: Gramedia, 1993 